Observatory, and gives the designations, positions, magnitudes, magnitude ranges, and spectral classification of fifteen new variable stars discovered in the regions covered by the Harvard maps Nos. 31 and 62 .

Names for the Three Jovian Asteroids.-Drs. Wolf and Kopff have chosen the three names Achilles, Hector, and Patroclus, respectively, to designate the three important minor planets (588) [1906 TG], [1907 XM], and [1906 VY] discovered by them at Heidelberg. Readers of these columns will cenember that the orbits of these three bodies have been found to extend as far from the sun as that of Jupiter (Astronomische Nachrichten, No. 4187, p. 192, June 29).

The Mira Maximum of igo6-7.-.-From a series of observations made at Utrecht, and extending from July 25 , 1906 , to March 4, 1907, Prof. Nijland found that the maximum brightness of Mira occurred on December 7 , when the magnitude was 2.0 . The preceding minimum was recorded or August 7 , and, as seen from the curve, was a very fat ne, from which a sharp rise to an exceptionally bright maximum took place. 'The previous maximum took place on January 3 , I906, so that the period between these two successive maxima was 338 days (Astronomische Nachrichten. p. II3, No. 4I83, June 14).

Solar P'ROMINENCE OBSERVATIONS in 1906.-The annual summary of: the results of the prominence observations made at Catania, for 1906; is published by Prof. Riccó in No. 5, vol. xxxvi. (p. 73), of the Memorie della Societì degli Spettroscopisti Italiani. The daily record is reproduced, and thep analysed, under the heads of the extension, height frequencies of the prominences, in the two hemispher for each month and quarter and for the year. The similarity of the size and distribution of the prominences recorded to those of the previous year indicates a stationary point characteristic of the maximum, whilst the greater frequency during March points to that month as being the actual month of solar prominence maximum.

\section{CONGRESS OF THE ROYAL INSTITUTE OF PUBLIC HEALTH.}

THE congress of the Royal Institute 1 Public Health, held this year at Douglas, Is1 of Man, from June 29 :a July 5, was presided ov 0 Lord Raglan, the Lieutenant-Ggernor of the course of his presiden 101 ady 0 gave a cordial welcome to the members of the for sus. He referred to the progress of sanitation ung he Victorian era, but pointed out that England Was handicapped in the hygienic struggle as compared with Continental nations owing to our exaggerated ideas of personal liberty.

Sir James Barr, in the course of his presidential address in the preventive medicine section, urged medical practitioners to take as deep an interest in sanitation as sanitarians. The health of a nation was its most valuable asset, and he would like to see all his adult countrymen able to handle a rifle and take part in the defence of their country should occasion arise, and he would encourage the military spirit as the best means of developing the moral and physical qualities of the nation. He urged that there should be State aid if needed for every child under sixteen to be properly fed and cared for. Huge trusts and millionaires were a danger to society, and part of their wealth should be appropriated by the State.

Prof. Sims Woodhead, in the section of bacteriology and chemistry, delivered an address on the subject of "antibodies," in which he traced the rise and development of bacteriology, and adduced statistical evidence on the value of diphtheria anti-toxin. Dr. Warrington, of Liverpool, introduced a discussion on cerebro-spinal fever, in which he advocated the isolation of cases and the disinfection of places in which the disease had occurred. Dr. Prudence Gaffitien read a paper on the causes of infantile mortality. She said the high infant death-rate was due to the ignorance of mothers, and advocated the prohibition of the use of soothing syrups, \&c. The Infant Life Protection Act was worse than useless; the State should provide for the inspection of foster or nurse children.

NO. I 967 , VOL. 76]
Prof. Hele Shaw delivered an address in the engineering and architectural section on road locomotion and the public health. He dealt chiefly with the new conditions occasioned by the advent of motor-cars; he admitted that the public had grievances arising from dust, odour, noise, and vibration, but claimed that much was being done to lessen these.

Dr. Sergeant, of the Lancashire County Council, opened a discussion on the milk supply, and a resolution was passed affirming the desirability of dairy regulations being made compulsory by the Local Government Board.

Many valuable papers were read on notification, tuberculosis, and sanatoria.

The social part of the congress was all that could be desired, and many excursions were made to the places of interest in the beautiful island. The congress dinner was presided over by Lord Raglan, and there was a gardenparty at Government House.

\section{RECENT CONTRIBUTIONS TO ELECTRIC WAVE TELEGRAPHY.}

PROF. FLEMING said that the achievements of electricwave telegraphy had not yet ceased to interest the public mind. In little more than eight years from the time when Mr. Marconi sent his first messages across the Erglish Channel, it had become an indispensable implement in naval warfare, and also a means of communication between ships and the shore, greatly adding to the safety of life and property at sea. At the present time practically the whole of the first- and second-class battleships of the British Navy are equipped with apparatus for electricwave telegraphy, and about $\mathrm{r} 30$ cruisers and smaller craft as well. The Marconi Company alone have fitted with their instruments nearly Ioo Atlantic liners and other mercantile vessels, and have an elaborate organisation by which all these ships are constantly in communication with the mainland during their voyage from port to port. Concurrently with this, an immense amount of scientific investigation has been carried on having for its object further improvements and the quantitative study of the phenomena. The object of the discourse was to make known some of these recent additions to knowledge.

A cardinal feature of electric-wave telegraphy is the vertical wire or wires at the transmitting and receiving stations, called the antenna. At the transmitting station high-frequency electric currents are set up in the sending antenna, and these create rapidly alternating electric and magnetic forces in the space around, which are propagated outwards from point to point with the velocity of light. Hence at certain distances, called a wave-length, these forces are reversed in the same way at the same instant. In electric-wave telegraphy the wave-lengths used lie between 200 feet and 20,000 feet or so, covering about eight octaves. The measurement of this wave-length is important. Prof. Fleming described an instrument of his own invention, called a cymometer, used for this purpose. It consists of a spiral of wire in series with a sliding tubular condenser, the circuit being completed by a copper bar. Across the terminals of the condenser is placed a neon vacuum tube. If the bar of the cymometer is placed near the transmitting antenna and the handle of the instrument moved, its capacity and inductance can be altered until it comes into tune with the antenna circuit. When this is the case the oscillations in the antenna create violent sympathetic oscillations in the cymometer, and the neon tube glows brilliantly. An index pointer moving over a scale then shows the wave-length of the waves radiated. The same instrument may be used to measure the wave-length of the arriving waves. Also it can be used to determine the decay of the oscillations in a train.

In spark telegraphy the oscillations are set up in the antenna by an electric discharge, and at each spark a group of oscillations takes place. These may come at the rate of ten to fifty groups per second, and each group may contain from ten to roo decadent oscillations. The cymometer can be used to draw a resonance curve by which the rate of decay and the number of the oscillations in a

1 Abstract of a discourse delivered at the Royal Instituticn on Fridar, May 24, by Prof. J. A. Fleming, F.R.S. 
train are determined. Methods have now been devised for creating undamped or nearly undamped oscillations. One method suggested is by the use of a high-frequency alternator, but the difficulty of constructing such a machine for a sufficiently high frequency is very considerable, and as yet only machines of small power have been made.

Prof. Elihu Thomson in 1892 patented a plan for producing a continuous current electric arc between metal terminals which. was acted upon by an air jet or magnetic field. He found that when the metal poles or spark balls were connected by a condenser in series with an inductance high-frequency osciliations were created in the latter circuit.

Mr. Duddell showed in Igoo that continuous undamped oscillations could be obtained when using, in place of the spark balls, an electric arc made between solid carbons. In $1903 \mathrm{Mr}$. Poulsen went a step farther. He formed the arc between a carbon terminal (negative) kept in rotation and a cold metal terminal (positive), and enclosed them in an atmosphere of hydrogen or coal gas and placed a strong magnetic field across the arc. The arc terminals being then shunted by a small condenser and an inductance, we have undamped high-frequency oscillations suitable for wireless telegraphy created in this latter circuit. Prof. Fleming gave an explanation of the reason for this effect, and showed that it was due to the form of the characteristic curve of the metal carbon arc. He compared the action to that of an organ pipe in which the energy is supplied by a steady jet of air corresponding to the continuous current arc, and this is made to set up aërial vibrations in the resonant organ pipe, equivalent to the condenser circuit, the vibrations in the pipe controlling and drawing their energy from the air jet. In applying the Poulsen method to wireless telegraphy, an antenna circuit is connected either inductively or directly with the condenser circuit.

Experiments were shown illustrating the production of high-frequency undamped electric oscillations in a long wire wound on an ebonite rod. Incidentally it was proved by an ingenious experiment with a neon vacuum tube that the oscillations are not really continuous, but cut up into irregular groups. In reference to the application of the Poulsen method to wireless telegraphy, Prof. Fleming said that the apparatus was more complicated and less easy to use than that for spark telegraphy. It was not true that undamped waves could not be picked up or tapped, and he proved that such advantages as the use of undamped waves in telegraphy might present were not due only to the transmitter, but to the conjoint use of a slightly damped receiver circuit.

Prof. Fleming did not agree with the opinion, confidently expressed in some quarters, that telegraphy by undamped waves would destroy spark telegraphy. Further, he pointed out that the electric arc was not the only method for producing undamped waves. He said that for some months past Mr. Marconi had been working out a purely mechanical method of producing continuous trains of electric waves suitable for wireless telegraphy, and had obtained considerable success. The method was exceedingly simple, and by means of it any existing station for spark telegraphy could be converted easily into a station sending out undamped electric-wave trains instead of intermittent damped trains.

The lecturer then passed on to explain some recent forms of electric-wave detector. When the waves sent out from the sending antenna fall on a receiving antenna they create in it secondary high-frequency oscillations, and these are detected by the use of some device called a wave detector. In addition to the coherer and the Marconi magnetic detector, the latter exclusively used in long-distance work, a receiver called an electrolytic detector is now much used. It consists of a vessel containing nitric acid in which is placed a platinum plate and an exceedingly fine platinum wire as the pair of electrodes. This cell is connected in series with a telephone and a voltaic battery, and when electric oscillations are passed through the cell they annul more or less the polarisation of the small electrode and create an increase of current, which in turn makes an audible signal in the telephone.

Signals are thus sent on the Morse code by interrupting the oscillations in the sending antenna. It has, how- ever, recently been found that this electrolytic detector, in conjunction with undamped-wave trains, affords a means of transmitting, not merely dots and dashes, but articulate speech sounds, and hence we have now electric-wave wireless telephony as an accomplished fact. Between Nauen and Berlin, a distance of about sixteen miles, successful experiments were recently carried out. From the transmitter continuous undamped waves of constant wavelength are sent out. The antenna is shunted by a microphone, so that words spoken to its diaplnagm vary the intensity of the wave train, but not its wave-length. At the receiving station an electrolytic detector is used, and the words spoken to the transmitter are reproduced at the receiving telephone. It is almost practicable at the present moment to speak audibly across the English Channel by wireless telephony, and within the bounds of possibility that at some time we may telephone without wires to a ship in the middle of the Atlantic.

Another new form of electric-wave detector is a glowlamp detector. A small carbon filament glow lamp has a metal cylinder placed in its bulb so as to surround, but not touch, the filament. This cylinder is connected to third terminal by a wire sealed through the glass. When the filament is rendered incandescent by a continuous current it throws off negatively charged corpuscles or electrons. The space between the filament and the cylinder will pass negative electricity from the filament to the cylinder, but not in the opposite direction. If, then, the oscillatory current in the receiving antenna, or secondary currents induced by them, are passed through the bulb from the carbon filament to the cylinder, only one constituent of the oscillation pass es, or the bulb rectifies the oscillations. We can then insert in series with the bulb either a telephone or galvanometer sensitive only to continuous currents and cause it to be affected.

This glow-lamp detector or oscillation valve has already proved itself to be a most sensitive long-distance receiver for wireless telegraphy. It is of great use in connection with undamped electric waves, as it affords a ready means for converting the high-frequency alternating current created in the receiving antenna into a continuous current detectable by a galvanometer or telephone. Prof. Fleming showed by an experiment that it enabled him to revive in another form elèctromagnetic induction telegraphy.

In the form in which this older system of wireless telegraphy was practised by Trowbridge, Preece, Lodge, and others, a closed primary circuit was traversed by a rather low-frequency alternating current viz."one of which the frequency lay within the limits of audible sound. In the modification proposed, a closed primary circuit earthed at one point is traversed by a very high-frequency current produced by the electric arc or other mechanical method. With high frequencies, say of 100,000 or so, no disturbance would be created in other earthed neighbouring telephonic or telegraphic circuits. The receiving circuit is a similar closed and syntonised circuit having a glow-lamp detector or oscillation valve and telephone inserted in it. The primary circuit affects the secondary circuit by magnetic induction, and also acts like a Fitzgerald closed magnetic oscillator, and throws off magnetic waves. With these modifications it is possible that induction telegraphy may be extended in range and free from the objection of dissurbing neighbouring telephonic circuits.

The lecturer then passed on to consider some advances made in directing electric waves in any required direction. All methods employing mirrors or reflectors are out of the question when long telegraphic electric waves are under consideration. Two methods at the present time presented practical advantages. In one, due to Mr. Marconi, the vertical upright antenna wires are replaced by antennæ having a short part vertical and their greater part horizontal. Such a bent antenna radiates best in the opposite direction to that in which its free or insulated end points. Hence, in accordance with the law of exchanges, which applies to clectric radiators, a bent antenna absorbs best electric waves coming from a direction opposite to that to which its free end points. Making use of such bent receiving and transmitting antennæ, Mr. Marconi has been able to limit the radiation in undesired directions, and also to locate the direction of invisible sending stations.

Another method, different in principle, has been devised 
by Prof. Braun, of Strassburg, who employs three vertical antennæ placed at equal distances, and sets up in these oscillations having certain assigned differences of phase. Hence, by the interference of these oscillations, the resultant radiation is made a maximum in a certain direction and zero in an opposite one.

In conclusion, some questions were dealt with concerning the varying opacity of our atmosphere to long electric waves and the effects of sunlight and radio-active matter in hindering their transmission. Although much valuable invention and discoveries in connection with this subject have rewarded the labours of workers in many lands, a glance round shows innumerable unsolved problems still remaining. Having regard to its importance for naval and maritime communication, scientific research in connection with wireless telegraphy is not merely desirable, but a positive duty, and it is to be hoped that the tendency to legislate for it by Acts of Parliament or international conferences will not impose shackles upon the freedom of investigation or of commercial work which alone can conduct us to the satisfactory solution of the difficulties and problems which yet remain.

\section{UNIVERSITY AND EDUCATIONAL \\ INTELLIGENCE.}

Birminghasx.-Mr. S. S. Dawson has been appointed to the chair of accounting vacated by Prof. Dicksee.

A sum of about roool. has been given by the Birmingham Chamber of Commerce to found a scholarship in the faculty of commerce.

ManCHESTER.-During recent years, with the increasing number of students who come from other parts of the country and from abroad the accommodation in the two halls of refidence fut modudents has had to be extended on seven occapos the opening of the nuidings of Hulm Hall in Victoria Park on July 6, which are to displace 0 older buildings in Plymouth Grove, marks an imporant advance, and rooms are immediately available for forty students, whilst this hall will later be extended to accommodate sixty.

ST. Andrews.-An important addition to the equipment of the Gatty Marine Laboratory has just been made by the presentation of the late Mrs. Alfred Gatty's extensive colleation of British and foreign marine algæ by her derughter, Mrs. Horatia Eden, of Rugby. Begun in 1848 at Hastings, this important collection was constantly added to during the life of the accomplished author of the "British Seaweeds." Moreover, Miss Catherine Cutley, of Exmouth, a well-known algologist, Prof. W. Harvey, Prof. Agardh, and others, largely increased its value by liberal donations. The collection is arranged, though not completely, according to Prof. Harvey's "Index Generum Algarum," and is accompanied by a valuable series of books of reference, many of them finely illustrated, by Greville, Harvey, Turner, Agardh, J. E. Gray, Frauenfeld, Mrs. Gatty, and others. The foregoing, with the collections of algæ by Mrs. McIntosh, Charles Howie, W. Knight, Dr. Drummond, \&c., previously in the laboratory, will, with the rich living series in the bay, give workers in algology facilities of no ordinary kind.

The King willopen the new buildings of University College School, $\}$ in Frognal, Hampstead, on Friday,
July 26.

The Right Hop. Ailwyn Fellowes will distribute the diplomas and prjes on Wednesday, July 24, at the SouthEastern Agricurttyal College, Wye, Kent.

DR. S. G. Rafuson has been appointed principal of the Battersea Polytechnic in succession to Mr. Sidney $\mathrm{H}$. Wells, who has been principal since the foundation of the institute 1893, and is resigning to take up the position of dusctor-general of the Department of Agriculture and Tefhnical Education for Egypt. Dr. Rawson is at present drector of education for Worcestershire, and was formerly principal of the Technical College, Huddersfield, and lecturer at Liverpool University.

No. 1967 , voL. 76$]$
A commrtTeE has been appointed by the Treasury to inquire and report upon the character of the work accomplished by the University of Wales and its constituent colleges, the financial position and lines of development of the colleges, and heir probable requirements for staff or otherwise. The members of the committee are:-Sir T. P.aleigh, K.C.S4 (chairman); Sir John Rhys, Principal of Jesus College, Oxford; Principal D. MacAlister, Glasgow Univerdty; Mr. F. G. Ogilvie, C.B.; Prof. W. S. McCormick; and Dr. Alexander Hill, Master of Downing College, Cambridge. Mr. G. L. Barstow, of the Treasury, will act as secretary to the committee.

THE Board of Education has issued its regulations for next session in connection with the work of technical schools, schools of art, and other day and evening schools and classes for further education. A prefatory memorandum directs attention to the changes introduced; but, before enumerating these, some remarks are made on the general condition of the work of the schools concerned. The experience 7 towns which have provided systematic and graded courso of instruction shows that a good supply of well-considered educational facilities may be made to foster a demand for these advantages without the application of compulsion in the matter of attendance. Another interesting fact is to find it specifically stated that it is regarded as one of the functions of the Board's inspectors to advise educational authorities, where evening and other schools are not so popular as they might be, as to the changes which would probably lead to improvement and to inform them where successful schools may. be found. A note has been added to the regulations with the object of making clear to local authorities that the classification of subjects and courses is in no sense a restriction upon the free adjustment of the subject-matter and methods of instruction in any class to the particular circumstances of the students. The necessity for keeping rural interests well in view throughout all educational work in country districts is now fully recognised, and the continuing need for Saturday and holiday courses for teachers who desire to improve their qualifications for duty in such areas is again pointed out.

\section{SOCIETIES AND ACADEMIES. LONDON.}

Royal Society, May 2.- "The Spontaneous Crystallisation of Binary Mixtures. Experiments on Salol and Betol." By Prof. H. A. Miers, F.R.S., and Miss F. Isaac.

The axthors have inferred from their experiments upon certain salts that a cooling supersaturated solution can at first only be made to crystallise by inoculation with a crystal of the solute, until a perfectly definite temperature is attained at which a mechanical stimulus, e.g. shaking or friction, will suffice to produce crystallisation. The temperature of this "spontaneous crystallisation" depends upon the strength of the solution as determined by a curve which they name the "supersolubility curve." They have now traced the complete freezing-point curve, and also the supersolubility curves for mixtures in all proportions of salol and betol, choosing these substances merely because they melt at convenient temperatures and do not form compounds or isomorphous mixtures. Salol melts at $42 \frac{1}{2}^{\circ}$ betol at $92^{\circ}$. The eutectic contains 78 per cent. salol, and freezes at $32 \frac{1}{2}^{\circ}$ by inoculation only.

Salol freezes spontaneously at $33^{\circ}$, betol at $79^{\circ}$; the supersolubility curves of their mixtures meet in the "hypertectic" mixture, containing 74 per cent. salol, for which the two substances freeze together spontaneously at $15^{\circ}$.

The freezing-point curve was determined by immersing a minute crystal in the cooling liquid and noting the temperature at which it just ceased to dissolve and began to grow.

The temperatures of spontaneous crystallisation were determined ( $\mathrm{r}$ ) by the crystallisation of the liquid on shaking or scratching when enclosed in a sealed tube, and also (2) by the dense shower of crystals which appears at the same temperature when the liquid is stirred in an open vessel. 